\title{
Association of single and multiple aneurysms with tobacco abuse: an @neurIST risk analysis
}

\author{
Bawarjan Schatlo, MD,,2 Oliver P. Gautschi, MD,1 Christoph M. Friedrich, PhD, ${ }^{3,7}$ \\ Christian Ebeling, MSc, ${ }^{4}$ Max Jägersberg, MD, ${ }^{1}$ Zsolt Kulscar, MD, ${ }^{5}$ Vitor Mendes Pereira, MD, 5,6 \\ Karl Schaller, MD, ${ }^{1}$ and Philippe Bijlenga, MD, PhD'
}

\begin{abstract}
${ }^{1}$ Department of Neurosurgery and Faculty of Medicine, and ${ }^{5}$ Department of Neuroradiology and Faculty of Medicine, University Hospital Geneva, Switzerland; ' $D$ Department of Neurosurgery, University Hospital Göttingen, Georg-August University, Göttingen; ${ }^{3}$ Department of Computer Science, University of Applied Sciences and Arts Dortmund; ${ }^{4}$ Fraunhofer Institute for Scientific Computing and Algorithms (SCAI), Sankt Augustin; ${ }^{7}$ Institute for Medical Informatics, Biometry, and Epidemiology (IMIBE), University Hospital Essen, Germany; and ${ }^{6}$ Department of Medical Imaging, Toronto Western Hospital, Toronto, Ontario, Canada
\end{abstract}

OBJECTIVE Although several studies have suggested that the incidence of intracranial aneurysms (IAs) is higher in smokers, the higher prevalence of subarachnoid hemorrhage $(\mathrm{SAH})$ in smokers remains uncertain. It is unclear whether smoking additionally contributes to the formation of multiple aneurysms and the risk of rupture. The aim of this study was to determine whether smoking is associated with IA formation, multiplicity, or rupture.

METHODS Patients from the prospective multicenter @neurIST database ( $n=1410 ; 985$ females [69.9\%]) were reviewed for the presence of $\mathrm{SAH}$, multiple aneurysms, and smoking status. The prevalence of smokers in the population of patients diagnosed with at least one IA was compared with that of smokers in the general population.

RESULTS The proportion of smokers was higher in patients with IAs (56.2\%) than in the reference population (51.4\%; $p<0.001)$. A significant association of smoking with the presence of an IA was found throughout group comparisons $(p=0.01)$. The presence of multiple IAs was also significantly associated with smoking $(p=0.003)$. A trend was found between duration of smoking and the presence of multiple IAs $(p=0.057)$. However, the proportion of smokers among patients suffering SAH was similar to that of smokers among patients diagnosed with unruptured IAs $(p=0.48)$.

CONCLUSIONS Smoking is strongly associated with IA formation. Once an IA is present, however, smoking does not appear to increase the risk of rupture compared with IAs in the nonsmoking population. The trend toward an association between duration of smoking and the presence of multiple IAs stresses the need for counseling patients with IAs regarding lifestyle modification.

https://thejns.org/doi/abs/10.3171/2019.4.FOCUS19130

KEYWORDS subarachnoid hemorrhage; smoking; multiple aneurysms; ruptured intracranial aneurysm

$\mathrm{T}$ HE prevalence of unruptured intracranial aneurysms (UIAs) in the adult population is estimated to be $3.2 \%$ (95\% CI 1.9\%-5.2\%). ${ }^{35,37}$ The proportion of diagnosed unruptured and asymptomatic IAs is increasing, ${ }^{2}$ likely due to a greater number of imaging facilities and improved technology. The decision of whether to treat an IA or to propose follow-up depends on many factors and remains a multidisciplinary task requiring systematic case-by-case evaluation. ${ }^{33}$ For patients who are followed up, one of the potentially modifiable cerebrovascular risk factors is smoking. A meta-analysis found that smoking may be the most important modifiable risk factor for subarachnoid hemorrhage (SAH), ${ }^{9}$ which was confirmed in a Cochrane systematic review. ${ }^{6}$ However, the two most recent longitudinal studies reported seemingly discordant observations on this matter. In the Finnish UIA long-term follow-up study involving 142 patients monitored for more than 3064 person-years, current smoking was associated with a significant increase in the rupture rate (nonsmokers $0.5 \%$ year, smokers $1.4 \%$ year; $\mathrm{p}=0.043$ ). ${ }^{20}$ The Unruptured Cerebral Aneurysm Study (UCAS) of Japan reported a smaller rupture rate for smokers than for nonsmokers

ABBREVIATIONS IA = intracranial aneurysm; SAH = subarachnoid hemorrhage; UCAS = Unruptured Cerebral Aneurysm Study; UIA = unruptured IA.

SUBMITTED February 23, 2019. ACCEPTED April 16, 2019.

INCLUDE WHEN CITING DOI: 10.3171/2019.4.FOCUS19130. 


\section{Presence of intracranial aneurysms in smokers}

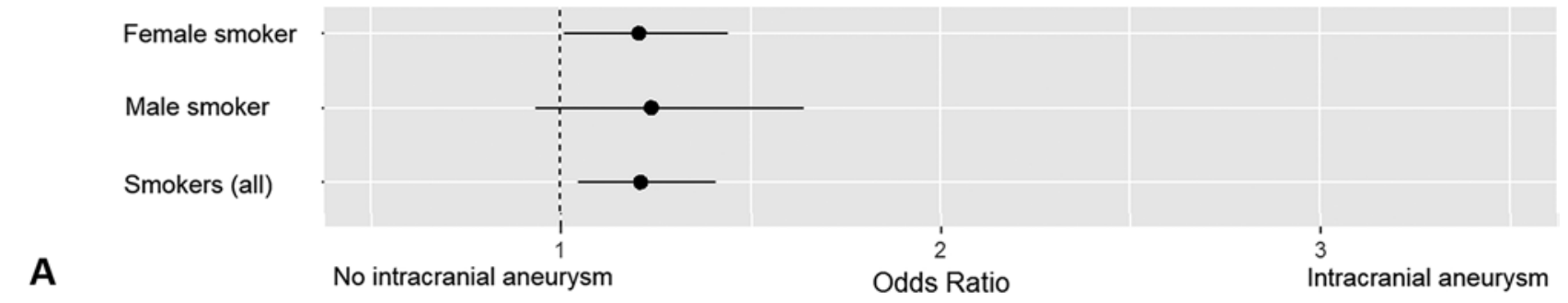

\section{Multiple aneurysm formation risk in smokers}

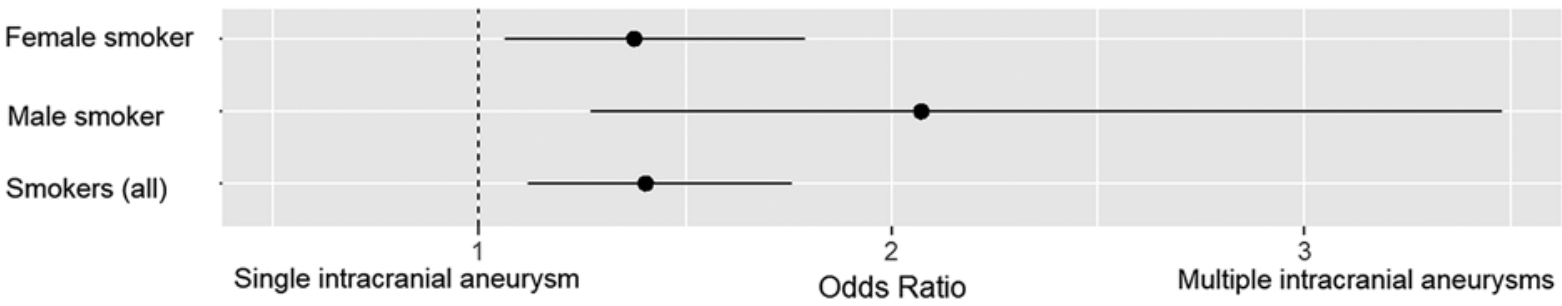

B

\section{Aneurysm rupture risk in smokers}

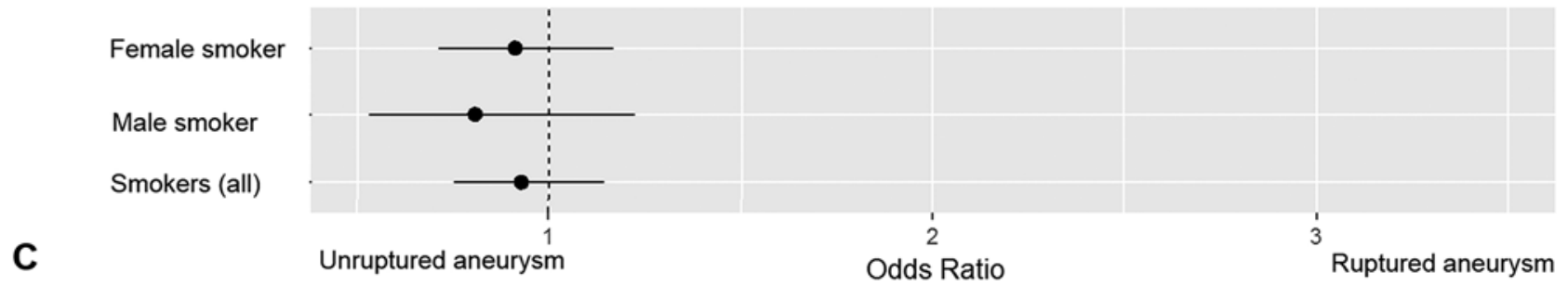

FIG. 1. The risk of aneurysm formation (A), multiple aneurysms $(\mathbf{B})$ and rupture risk $(\mathbf{C})$ is depicted in ever smokers stratified by sex. Overall, aneurysms occur more likely in smokers. In contrast, there appears to be no higher risk of rupture of IAs in patients who smoke than those in patients who do not.

(5720 patients, 11,660 aneurysm-years of follow-up; nonsmokers $1 \% /$ year [95\% CI 0.8\%/year-1.2\%/year], smokers $0.7 \% /$ year [ $[95 \%$ CI $0.4 \% /$ year-1.2\%/year] $) .{ }^{27}$ This discrepancy can be resolved by the knowledge that in the Finnish study, the conclusion was only based on current smokers, while the Japanese study had a negligible rate of current smokers. In addition, a case-control study that compared 206 patients with IAs and 547 controls found an additive effect of smoking and hypertension on the risk of rupture. The authors concluded that whether the risk of SAH is increased by an increased risk of aneurysm formation or also through an increased risk of rupture remains to be elucidated (Fig. 1). ${ }^{37}$

Several retrospective studies have addressed the question of whether smoking is associated with IAs, and they all confirmed the link. In one study, a retrospective Chinese cohort of 251 patients with IAs was compared with 338 patients with other cerebral conditions. ${ }^{14}$ The analysis revealed that smoking contributed to the likelihood of harboring an IA, along with sex, elevated blood glucose, and arterial hypertension. A Japanese retrospective case-control study analyzed 266 patients with UIAs, 798 patients with ruptured aneurysms, and 798 controls. ${ }^{16}$ Hyperlipidemia, heart disease, diabetes, and smoking were associated with the presence of a UIA. Rupture of aneurysms was associated with smoking only if the ruptured and UIA groups were directly compared without prior age and sex matching, raising the question of whether the association was due to imbalanced baseline parameters. ${ }^{16} \mathrm{~A}$ retrospective case-control study including 300 patients with and 900 patients without IAs addressed the impact of statin use. It confirmed the notion that smoking is associated with the presence of UIAs ${ }^{25}$ but not with rupture. In a comparison of 206 aneurysm patients with 574 random controls, active smoking, hypertension, and a family history of stroke were associated with IAs. Inverse correlations were found for hypercholesterolemia and physical exercise. ${ }^{36}$

It remains unclear to what extent previous reports were exclusively focusing on aneurysmal SAH and to what extent longitudinal studies were affected by inclusion biases, e.g., more readily offering intervention to smokers. Moreover, the higher incidence of SAH in Finland and Japan ${ }^{13}$ limits the applicability of studies in these regions to other populations. In the context of the prospective, multicenter @ neurIST project, information about patients recruited with IAs on a European scale was collected from November 1, 2006, onward. ${ }^{8}$ The aim of the present study was to assess whether smoking is associated with IA formation and whether smoking increases the risk of subsequent rupture. 


\section{Methods}

This analysis is based on the @neurIST database (November 1,2006, to March 31, 2012) that includes consecutive patients diagnosed with IAs from Geneva University Hospital up to February 1, 2016. Ethics committee approval was obtained from all participating centers, and all patients or their legal guardians gave written permission for their inclusion.The@neurIST project includes patients with incidental, symptomatic, or ruptured IAs and covers demographic, clinical, and imaging parameters. For the present study, we distinguished between patients followed up or treated for UIAs (unruptured group) and those with SAH (ruptured group). Age, sex, smoking status, and number of aneurysms (dichotomized into single and multiple) were recorded, and data sets of 1410 consecutive patients with full data were included.

\section{Smoking Status}

We adopted the standard definition proposed by the US Centers for Disease Control and Prevention ${ }^{31}$ to categorize patients as follows: never smokers, adults who have never smoked a cigarette or who smoked fewer than 100 cigarettes in their entire lifetime; former smokers, adults who have smoked at least 100 cigarettes in their lifetime, but say they currently do not smoke; nonsmokers, adults who currently do not smoke cigarettes, including both former smokers and never smokers; current smokers, adults who have smoked 100 cigarettes in their lifetime and currently smoke cigarettes every day (daily) or some days (nondaily); and current nonsmokers, all individuals who are not "current smokers."

\section{Reference Population}

The prevalence of smoking in the 1410 IA patients was compared with that of 302,095 controls adjusted for sex, age, and country of origin based on Swiss and European population surveys. ${ }^{22,41}$ Odds ratios comparing selected groups of patients were used to address each specific question. To consider confounding effects, subgroup analysis and multiple logistic regressions were performed. The analysis was conducted using the statistical programming language R (version 3.4, R-Project 2017). Odds ratios and confidence intervals were calculated, and the significance level was set at $\mathrm{p}<0.05$. The Wilcoxon rank-sum test was used to assess differences in smoking duration between single and multiple IA groups.

\section{Results}

The study cohort included 1410 patients (985 females, $69.9 \%$ ) with a mean age of $55.7 \pm 13$ years (SD). Of 1410 patients, 785 patients presented with SAH (55.7\%). Multiple IAs were present in 478 patients $(33.9 \%)$. Seven hundred ninety-three patients $(56.2 \%)$ had a history of ever smoking and 468 (33.2\%) were actively smoking at the time of recruitment. Baseline parameters are displayed in Table 1.

Smoking habits in the reference populations were derived from European national averages and adjusted to the countries of participating centers. The proportion of

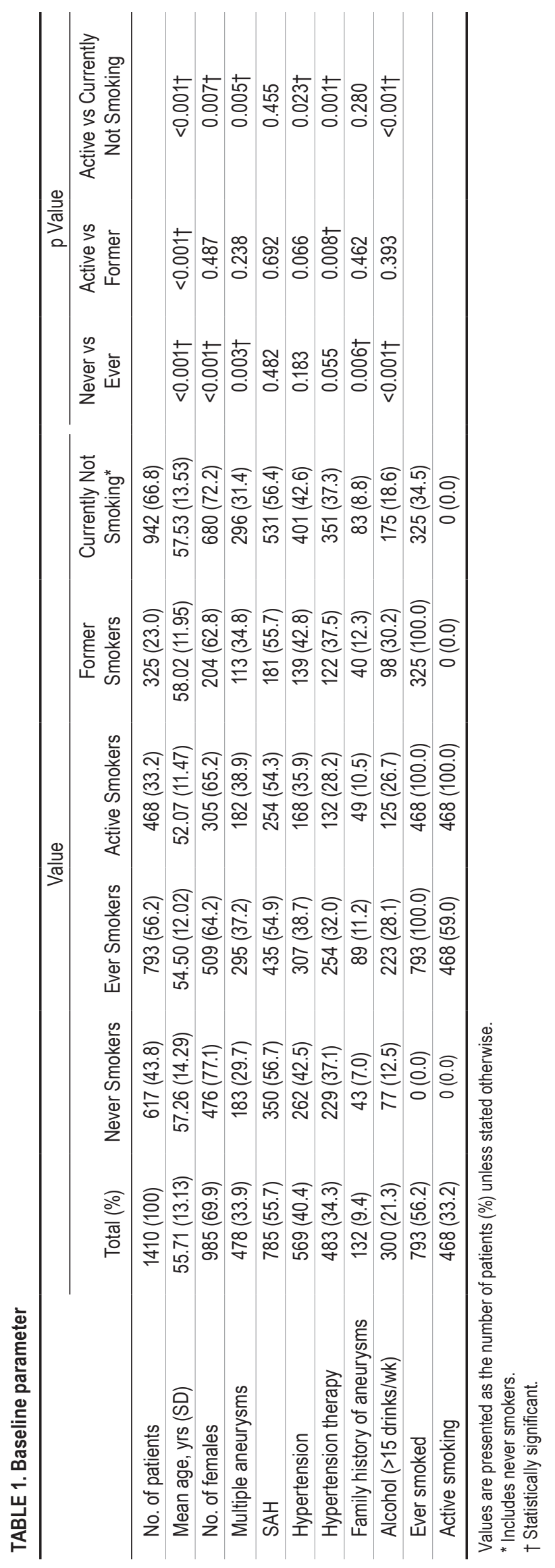

Neurosurg Focus Volume 47 • July 2019 
TABLE 2. Proportion of smokers in the reference population and in the @neurist cohort

\begin{tabular}{cccccccc}
\hline & \multicolumn{2}{c}{$\begin{array}{c}\text { Reference Population } \\
(n=302,095)\end{array}$} & & \multicolumn{3}{c}{$\begin{array}{c}\text { Full Cohort } \\
(\mathrm{n}=1410)\end{array}$} \\
\cline { 2 - 3 } \cline { 6 - 8 } & Total & Female & Male & & Total & Female & Male \\
\hline $\begin{array}{c}\text { Never } \\
\text { smokers }\end{array}$ & $48.6 \%$ & $53.0 \%$ & $38.2 \%$ & & $43.8 \%$ & $48.3 \%$ & $33.2 \%$ \\
\hline $\begin{array}{c}\text { Ever smok- } \\
\text { ers }\end{array}$ & $51.4 \%$ & $47.0 \%$ & $61.7 \%$ & $56.2 \%$ & $51.7 \%$ & $66.8 \%$ \\
\hline $\begin{array}{c}\text { Active } \\
\text { smokers }\end{array}$ & $26.7 \%$ & $24.7 \%$ & $31.3 \%$ & $33.2 \%$ & $30.9 \%$ & $38.4 \%$ \\
\hline $\begin{array}{c}\text { Former } \\
\text { smokers }\end{array}$ & $24.8 \%$ & $22.4 \%$ & $30.4 \%$ & $23.0 \%$ & $20.7 \%$ & $28.5 \%$ \\
\hline
\end{tabular}

ever smokers was higher in patients with IAs $(56.2 \%)$ than in the general population $(51.4 \%$; $<<0.001)$. In accordance with the data collected for our study population, the proportion of smokers in the reference population was divided into the categories of the Centers for Disease Control and Prevention and is displayed in Table 2.

A significant association of smoking with the presence of an IA was found throughout group comparisons: ever versus never (OR 1.21 [95\% CI 1.05-1.40], $\mathrm{p}=0.01 ; \mathrm{n}=$ 1410), active versus never (OR 1.38 [95\% CI 1.16-1.64], $\mathrm{p}$ $=0.002 ; \mathrm{n}=1085)$, and active versus all other groups (OR 1.37 [95\% CI 1.16-1.61], $\mathrm{p}=0.001 ; \mathrm{n}=1410$ ) (Table 3).

The presence of multiple IAs was also significantly associated with smoking: ever versus never (OR 1.40 [95\% CI 1.12-1.76], $\mathrm{p}=0.003 ; \mathrm{n}=1410)$, active versus never (OR 1.40 [95\% CI 1.12-1.76], $\mathrm{p}=0.003 ; \mathrm{n}=1410)$, and active versus all other groups (OR 1.39 [95\% CI 1.10-1.75], $\mathrm{p}=$ $0.005 ; \mathrm{n}=1410)($ Table 3$)$.

In contrast, the proportion of smokers suffering $\mathrm{SAH}$ was similar to that of nonsmoking patients with IAs: ever versus never (OR 0.92 [95\% CI 0.745-1.15], $\mathrm{p}=0.48$; $\mathrm{n}=$ 1410), active versus never (OR 0.91 [95\% CI 0.71-1.15], p $=0.42 ; \mathrm{n}=1085)$, and active versus all other groups (OR 0.92 [95\% CI 0.73-1.15], $\mathrm{p}=0.46 ; \mathrm{n}=1410$ ). Further group comparisons are outlined in Tables 4 and 5.

Duration of smoking showed a trend toward an association with multiple IAs. However, the difference in duration of smoking was small, at only 1.5 years' difference (solitary IA: $24.7 \pm 12.7$ years; multiple IAs: $26.4 \pm 12.0$ years $[p=0.057])$. Gradual stepwise increases in the risk of multiple IAs were seen as the duration of smoking increased (Fig. 2).

\section{Discussion}

\section{Smoking Is Associated With the Formation of IAs}

The analysis of this large European sample indicates that smoking is associated with a higher likelihood of having an IA. The increased likelihood of smokers having an IA may be due to several factors. The biological effects of smoking may change blood viscosity, modify wall shear stress, and/or affect vessel wall remodeling..$^{32}$ It may directly act on the vessel wall, increasing myeloperoxidase generation ${ }^{29}$ or tumor necrosis factor- $\alpha$ signaling, ${ }^{18}$ which causes inflammation and remodeling. Interactions between genes and smoking have been reported in the $\mathrm{Fa}$ milial Intracranial Aneurysms genome screen study. Genetic variation on chromosome arm $7 \mathrm{p}(60 \mathrm{cM})$ and smoking showed logarithmic odds ratios increasing from 0.7 to $4.1(\mathrm{p}<0.001)$ when using a model-independent linkage analysis or an ordered subset analysis taking smoking into account. The observation suggests a strong association favoring IA formation in patients affected by both a genetic predisposition and tobacco consumption. ${ }^{7}$ A multitude of factors results in IA formation and growth over a lifetime. Although the identification of an individual at risk of having an IA based on genetic and lifestyle data would be desirable, rigorous screening criteria cannot presently be derived from the data at hand.

\section{Current Knowledge on Smoking and Aneurysm Formation}

Smoking has been shown to be associated with the formation of de novo aneurysms, ${ }^{15,40}$ aneurysm multiplicity, ${ }^{26}$ and aneurysm growth. ${ }^{5}$ Association with IA rupture, however, remains controversial. In a case-control study comparing patients with ruptured IAs to patients with unruptured IAs, current smoking was strongly associated with SAH (OR 2.2 [95\% CI 1.85-2.6]) in comparison with never smokers. Former smoking was also significantly associated with rupture, and duration of cessation had no effect on IA rupture (OR 1.6 [95\% CI 1.3-1.9]). ${ }^{4} \mathrm{~A}$ similar study observed a strong dose-response relationship for intensity and duration of smoking with risk of IA rupture, but in contrast found no association of former smoking with IA rupture..$^{0}$ Overall, it seems that IAs diagnosed in smokers are more frequently located at the middle cere-

TABLE 3. Risks of aneurysm formation, multiple aneurysms, and rupture

\begin{tabular}{|c|c|c|c|c|c|c|c|c|c|}
\hline & \multicolumn{3}{|c|}{ Aneurysm Formation Risk } & \multicolumn{3}{|c|}{ Multiple Aneurysm Formation Risk } & \multicolumn{3}{|c|}{ Rupture Risk } \\
\hline & OR $(95 \% \mathrm{Cl})$ & p Value & $\begin{array}{c}\text { No. of } \\
\text { Patients }\end{array}$ & OR $(95 \% \mathrm{Cl})$ & $\mathrm{p}$ Value & $\begin{array}{c}\text { No. of } \\
\text { Patients }\end{array}$ & OR $(95 \% \mathrm{Cl})$ & $\begin{array}{c}p \\
\text { Value }\end{array}$ & $\begin{array}{c}\text { No. of } \\
\text { Patients }\end{array}$ \\
\hline Ever vs never & $1.21(1.05-1.40)$ & 0.01 & 1410 & $1.40(1.12-1.76)$ & 0.003 & 1410 & $0.92(0.745-1.15)$ & 0.48 & 1410 \\
\hline Active vs never & $1.38(1.16-1.64)$ & 0.002 & 1085 & $1.40(1.12-1.76)$ & 0.003 & 1410 & $0.91(0.71-1.15)$ & 0.42 & 1085 \\
\hline Active vs currently not smoking & $1.37(1.16-1.61)$ & 0.001 & 1410 & $1.39(1.10-1.75)$ & 0.005 & 1410 & $0.92(0.73-1.15)$ & 0.46 & 1410 \\
\hline Former vs never & $1.03(0.86-1.25)$ & 0.72 & 942 & $1.26(0.94-1.68)$ & 0.11 & 942 & $0.95(0.73-1.26)$ & 0.76 & 942 \\
\hline Active vs former & $1.34(1.06-1.71)$ & 0.01 & 793 & $1.19(0.89-1.60)$ & 0.24 & 793 & $0.94(0.71-1.26)$ & 0.69 & 793 \\
\hline Female vs male & $2.32(1.99-2.70)$ & $<0.001$ & 1410 & $1.62(1.27-2.09)$ & 0.0001 & 1410 & $0.69(0.55-0.88)$ & 0.002 & 1410 \\
\hline
\end{tabular}


TABLE 4. Proportion of single and multiple aneurysms by sex and smoking status

\begin{tabular}{lccc}
\hline & \multicolumn{3}{c}{ No. of Patients (\%) } \\
\cline { 2 - 4 } & Never Smoked & Ever Smoked & Total \\
\hline Female & $158(43)$ & $207(57)$ & 365 \\
\hline Multiple & $318(51)$ & $302(49)$ & 620 \\
\hline Single & & & \\
\hline Male & $25(22)$ & $88(78)$ & 113 \\
\hline Multiple & $116(37)$ & $196(63)$ & 312 \\
\hline Single & & & \\
\hline Overall & $183(38)$ & $295(62)$ & 478 \\
\hline Total multiple & $434(47)$ & $498(53)$ & 932 \\
\hline Total single & $617(44)$ & $793(56)$ & 1410 \\
\hline Total & & &
\end{tabular}

bral artery bifurcation and the anterior communicating artery complex than IAs diagnosed in nonsmokers. ${ }^{21} \mathrm{De}$ novo aneurysm formation was not found to be associated with smoking status in patients who had already suffered an IA rupture. ${ }^{38}$ Passive smoking seems to not be associated with a higher risk of IA rupture in nonsmoking women in China. ${ }^{11}$

\section{Transverse Versus Longitudinal Study}

Two options exist to gain insight into the risk of smoking in a population. The most appealing, though lengthy, possibility would be a longitudinal study in which patients fulfilling a certain criterion-in this case, being diagnosed with an IA - are followed up until rupture or death of other causes. One such example is a longitudinal study on the natural course of spondylolisthesis, which was begun in 1955 and concluded in 2003. ${ }^{1}$ A novel source of longitudinal data stems from a Korean health screening and promotion program. As part of this effort, more than 18,000 subjects were screened using MRA, yielding a UIA rate of about $2 \%$. The rate of smokers in the UIA group (21\%) was not significantly higher than that in the unaffected group $(18 \%)$. Interestingly, when split by vascular territories, the presence of a middle cerebral artery aneurysm was independently affected by smoking. ${ }^{21}$ This study did not provide a longitudinal follow-up and therefore has thus far not produced data on the risk of rupture. A meaningful longitudinal design requires a decade-long commitment and will be one of the future fruits of ongoing efforts in maintaining multicenter registries such as @ neurIST ${ }^{2}$ and the Swiss study on SAH (Swiss SOS) ${ }^{30}$ Until data from longitudinal studies become available, however, the transverse approach remains the most useful tool to assess the association of specific factors with the risk of a certain event, in this case, IA rupture. We therefore performed a transverse comparison of respective proportions of smokers in normal population versus patients with UIAs and ruptured IAs, respectively. These data are unique in that they are the result of a decade-long, high-quality prospective data collection drawing from multiple ethnicities within one continent.
TABLE 5. Proportion of ruptured and unruptured aneurysms by sex and smoking status

\begin{tabular}{cccc}
\hline & \multicolumn{3}{c}{ No. of Patients (\%) } \\
\cline { 2 - 4 } & Never Smoked & Ever Smoked & Total \\
\hline Female & & & \\
\hline Unruptured & $218(47)$ & $245(53)$ & 463 \\
\hline Ruptured & $258(49)$ & $264(51)$ & 522 \\
\hline Male & & & \\
\hline Unruptured & $49(30)$ & $113(70)$ & 162 \\
\hline Ruptured & $92(35)$ & $171(65)$ & 263 \\
\hline Overall & & & \\
\hline Total unruptured & $267(43)$ & $358(57)$ & 625 \\
\hline Total ruptured & $350(45)$ & $435(55)$ & 785 \\
\hline Total & $617(44)$ & $793(56)$ & 1410 \\
\hline
\end{tabular}

\section{Influence of Smoking on Rupture: Biological Bias?}

In the general population, smokers have a higher overall risk of suffering SAH in their lifetime. ${ }^{24}$ Interestingly and in contrast with the finding of Juvela et al. ${ }^{20}$ but in concordance with the observation in UCAS Japan, ${ }^{27}$ our data do not support the concept that smokers with an IA have a higher relative risk of rupture than nonsmoking patients with IAs. However, our data and those of others provide robust evidence that there are more smokers in the population of patients with IAs than in the normal population. Since smokers are overrepresented in the population of patients with IAs, their risk of suffering an SAH is greater than that of nonsmokers in the general population. The latter observation seems to be solely the result of the increased prevalence of IAs in the smoking population..$^{24}$ Therefore, a selection bias may be inherent when comparing the smoking population with their nonsmoking counterparts, and special care needs to be taken to use adequate patient groups to perform comparisons and derive conclusions. A more recent Finnish study attempted to compare the decreasing rates of tobacco abuse with the declining incidence of SAH, but the authors conceded that an association between both observed phenomena is difficult to ascertain. ${ }^{23}$ While our analysis reveals that stopping smoking will not reduce the risk of SAH from a present IA, it is also suggestive that duration of smoking may be associated with de novo IA formation. The Rochester epidemiology study found that the average size of IAs that did rupture was $7 \mathrm{~mm}, 39$ but ISUIA (International Study on Unruptured Intracranial Aneurysms) and other studies found that aneurysms smaller than $7 \mathrm{~mm}$ rarely ruptured. ${ }^{17}$ This has led to the hypothesis that aneurysms form over a very short period of time. In this short period of growth, risk of rupture is at its peak, followed by a stable phase. Our data are consistent with this hypothesis and that quitting smoking may not necessarily affect the risk of subsequent rupture after an IA has passed this initial period of risk during formation. ${ }^{17,39}$ The practical question of whether smoking cessation will have a tangible effect on the rupture rate will require longitudinal analysis of the presented cohort in the years to come, taking into account an un- 


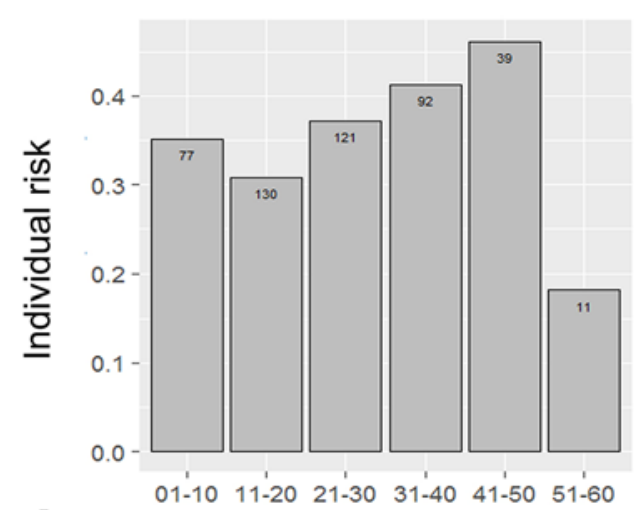

A Duration of smoking (years)

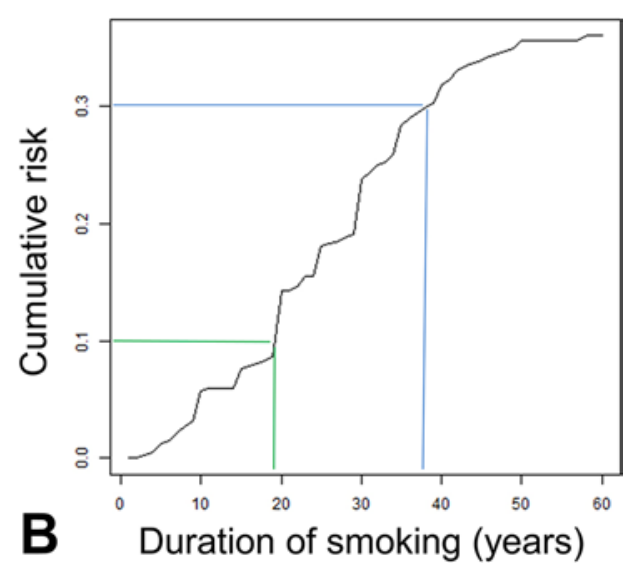

FIG. 2. Multiple aneurysms and duration of smoking. A: Bar graph depicting the individual likelihood of having multiple aneurysms (y-axis) over duration of smoking (in 10-year increments; $x$-axis). Visually, the risk of having multiple compared with solitary aneurysms increases linearly with smoking duration. Duration of smoking was not available for 8 patients. B: Cumulative risk (y-axis) is depicted over period of smoking (x-axis). The risk of having multiple aneurysms steadily increases with each year of smoking. While the risk of having multiple aneurysms after less than 20 years of smoking increases by less than $10 \%$ (green lines), another 20 years of smoking triples the risk of multiple aneurysms to $30 \%$ (blue lines).

avoidable bias that active smokers are more likely to be offered treatment than nonsmokers or smokers who quit and therefore have shorter follow-ups. Aneurysm growth has been suggested as a surrogate marker for aneurysm rupture. Prospective longitudinal observations, although reporting a trend, have thus far failed to demonstrate a strong and significant effect of smoking on aneurysm growth. ${ }^{3}$

\section{Multiple Aneurysms}

In a series of $266 \mathrm{SAH}$ patients, ${ }^{19}$ smokers were found to have a higher rate of multiple IAs. Our sample population, which was was larger, included multiple European centers, and was obtained in a more recent assessment period, confirmed that smoking is associated with the formation of multiple IAs. We observed that the duration of smoking was associated-although not significantly - with an increase in the proportion of patients with multiple IAs. Smoking males had an almost 2-fold likelihood of developing multiple IAs. In contrast, the likelihood of females developing multiple IAs was low enough to miss significance. Male sex and smoking are risk factors for other diseases of the vessel wall such as abdominal aortic aneurysms. ${ }^{34}$

\section{Aneurysm Growth}

Regarding the question of whether aneurysms in smoking patients grow differently, there currently are insufficient data. The problem is that aneurysm growth is a relatively rare event. A recent analysis from our group revealed a $2.6 \%$ yearly aneurysm growth rate in patients followed up for unruptured intracranial aneurysms. ${ }^{12}$ Due to the small number of events (growth) observed $(n=32)$, there were no detectable differences in smoking habits between stable and unstable aneurysm patients. Using data from 10 studies on 2086 cases, we found no association between aneurysm growth in smokers versus nonsmokers $($ OR 1.2 [95\% CI 0.9-1.6], $\mathrm{p}=0.23) .^{12}$

\section{Patient Counseling}

The body of data suggesting that smoking contributes to de novo formation of IAs is consolidating. The lifetime risk of suffering an SAH is higher in smokers and appears to correlate with the quantity of tobacco abuse. ${ }^{24}$ Contrary to the Finnish cohort, which showed that smoking increased the rupture risk, ${ }^{20}$ but in keeping with the Japanese data, which found no significant, if not an inverse, association, ${ }^{27}$ our data do not warrant a clear-cut statement that an IA in a smoking patient is more likely to rupture than that in a nonsmoking patient. With more patients, the present study may have found a trend toward a potential for increased de novo IA formation in smokers, but this will remain speculative. These data alone are therefore unlikely to deter patients with UIAs to abstain from smoking. The association of smoking with a higher likelihood of suffering SAH or developing an IA seems anecdotal compared with the scientifically established causal effect of smoking on other diseases, which results in 440,000 deaths annually in the United States alone. Among others, diseases that are now known to be caused directly by smoking include several types of cancer, atherosclerosis, abdominal aortic aneurysms, stroke, chronic obstructive pulmonary disease, complications in pregnancy, cataracts, and increased risk of surgical complications and hip fractures, as reviewed in the comprehensive report of the surgeon general on smoking. ${ }^{28}$ It will remain the duty of cerebrovascular specialists to address the topic with affected patients based on the general health risks in addition to the data on IA and stroke.

\section{Conclusions}

Providing information to patients and recommendations on lifestyle modifications supported by scientific observations are of paramount importance in daily neurovascular practice. While our data do not support that quitting smoking reduces the risk of IA rupture, they underline that smoking cessation would reduce the formation of new IAs, 
which may thereby lower the risk of subsequent rupture. This finding may reflect a potentially different biological background of IAs in smokers and nonsmokers and in IA formation and rupture.

\section{Acknowledgments}

We thank Daniel Woo for his careful manuscript review and comments.

This study was supported by the 6th framework program of the European Commission @ neurIST project (www.aneurist.org) FP6-IST-2004-027703 and by the AneuX project (www.aneux. ch) supported by SystemsX.ch and evaluated by the Swiss National Science Foundation (SysX.ch 2014/261). Neither sponsor nor funder had any part in study design, data collection, analysis or reporting, which were organized by the project board. All authors had full access to all the data in the study and share final responsibility for the decision to submit for publication.

\section{References}

1. Beutler WJ, Fredrickson BE, Murtland A, Sweeney CA, Grant WD, Baker D: The natural history of spondylolysis and spondylolisthesis: 45-year follow-up evaluation. Spine (Phila Pa 1976) 28:1027-1035, 2003

2. Bijlenga P, Ebeling C, Jaegersberg M, Summers P, Rogers A, Waterworth A, et al: Risk of rupture of small anterior communicating artery aneurysms is similar to posterior circulation aneurysms. Stroke 44:3018-3026, 2013

3. Bor AS, Tiel Groenestege AT, terBrugge KG, Agid R, Velthuis BK, Rinkel GJ, et al: Clinical, radiological, and flow-related risk factors for growth of untreated, unruptured intracranial aneurysms. Stroke 46:42-48, 2015

4. Can A, Castro VM, Ozdemir YH, Dagen S, Yu S, Dligach $\mathrm{D}$, et al: Association of intracranial aneurysm rupture with smoking duration, intensity, and cessation. Neurology 89:1408-1415, 2017

5. Chien A, Callender RA, Yokota H, Salamon N, Colby GP, Wang AC, et al: Unruptured intracranial aneurysm growth trajectory: occurrence and rate of enlargement in 520 longitudinally followed cases. J Neurosurg [epub ahead of print March 1, 2019. DOI: 10.3171/2018.11.JNS181814]

6. Clarke M: Systematic review of reviews of risk factors for intracranial aneurysms. Neuroradiology 50:653-664, 2008

7. Deka R, Koller DL, Lai D, Indugula SR, Sun G, Woo D, et al: The relationship between smoking and replicated sequence variants on chromosomes 8 and 9 with familial intracranial aneurysm. Stroke 41:1132-1137, 2010

8. Dunlop R, Arbona A, Rajasekaran H, Lo Iacono L, Fingberg J, Summers P, et al: @ neurIST_chronic disease management through integration of heterogeneous data and computer-interpretable guideline services. Stud Health Technol Inform 138:173-177, 2008

9. Feigin VL, Rinkel GJ, Lawes CM, Algra A, Bennett DA, van Gijn J, et al: Risk factors for subarachnoid hemorrhage: an updated systematic review of epidemiological studies. Stroke 36:2773-2780, 2005

10. Feng X, Qian Z, Zhang B, Guo E, Wang L, Liu P, et al: Number of cigarettes smoked per day, smoking index, and intracranial aneurysm rupture: a case-control study. Front Neurol 9:380, 2018

11. Feng X, Wang L, Guo E, Zhang B, Qian Z, Wen X, et al: Passive smoking is not associated with risk of intracranial aneurysm rupture in nonsmoking women. World Neurosurg 107:716-723, 2017

12. Gondar R, Gautschi OP, Cuony J, Perren F, Jägersberg M, Corniola MV, et al: Unruptured intracranial aneurysm follow-up and treatment after morphological change is safe: observational study and systematic review. J Neurol Neurosurg Psychiatry 87:1277-1282, 2016

13. Greving JP, Wermer MJ, Brown RD Jr, Morita A, Juvela S, Yonekura M, et al: Development of the PHASES score for prediction of risk of rupture of intracranial aneurysms: a pooled analysis of six prospective cohort studies. Lancet Neurol 13:59-66, 2014

14. Gu YX, Chen XC, Song DL, Leng B, Zhao F: Risk factors for intracranial aneurysm in a Chinese ethnic population. Chin Med J (Engl) 119:1359-1364, 2006

15. Hu S, Yu N, Li Y, Hao Z, Liu Z, Li MH: A meta-analysis of risk factors for the formation of de novo intracranial aneurysms. Neurosurgery [epub ahead of print], 2018

16. Inagawa $\mathrm{T}$ : Risk factors for the formation and rupture of intracranial saccular aneurysms in Shimane, Japan. World Neurosurg 73:155-164, e23, 2010

17. International Study of Unruptured Intracranial Aneurysms Investigators: Unruptured intracranial aneurysms-risk of rupture and risks of surgical intervention. N Engl J Med 339:1725-1733, 1998

18. Jayaraman T, Paget A, Shin YS, Li X, Mayer J, Chaudhry H, et al: TNF-alpha-mediated inflammation in cerebral aneurysms: a potential link to growth and rupture. Vasc Health Risk Manag 4:805-817, 2008

19. Juvela S: Risk factors for multiple intracranial aneurysms. Stroke 31:392-397, 2000

20. Juvela S, Poussa K, Lehto H, Porras M: Natural history of unruptured intracranial aneurysms: a long-term follow-up study. Stroke 44:2414-2421, 2013

21. Kang HG, Kim BJ, Lee J, Kim MJ, Kang DW, Kim JS, et al: Risk factors associated with the presence of unruptured intracranial aneurysms. Stroke 46:3093-3098, 2015

22. Keller R, Radtke T, Krebs H, Hornung R: Der Tabakkonsum der Schweizer Wohnbevölkerung in den Jahren 2001 bis 2010. Tabakmonitoring-Schweizerische Umfrage zum Tabakkonsum. Zürich: Psychologisches Institut der Universität Zürich, Sozial- und Gesundheitspsychologie, 2011 (www.tabakmonitoring.ch) [Accessed May 13, 2019]

23. Korja M, Lehto H, Juvela S, Kaprio J: Incidence of subarachnoid hemorrhage is decreasing together with decreasing smoking rates. Neurology 87:1118-1123, 2016

24. Longstreth WT Jr, Nelson LM, Koepsell TD, van Belle G: Cigarette smoking, alcohol use, and subarachnoid hemorrhage. Stroke 23:1242-1249, 1992

25. Marbacher S, Schläppi JA, Fung C, Hüsler J, Beck J, Raabe A: Do statins reduce the risk of aneurysm development? A case-control study. J Neurosurg 116:638-642, 2012

26. McDowell MM, Zhao Y, Kellner CP, Barton SM, Sussman E, Claassen J, et al: Demographic and clinical predictors of multiple intracranial aneurysms in patients with subarachnoid hemorrhage. J Neurosurg 128:961-968, 2018

27. Morita A, Kirino T, Hashi K, Aoki N, Fukuhara S, Hashimoto $\mathrm{N}$, et al: The natural course of unruptured cerebral aneurysms in a Japanese cohort. N Engl J Med 366:2474-2482, 2012

28. Office of the Surgeon General (US); Office on Smoking and Health (US): The Health Consequences of Smoking: A Report of the Surgeon General. Atlanta: Centers for Disease Control and Prevention, 2004

29. Rudolph TK, Rudolph V, Baldus S: Contribution of myeloperoxidase to smoking-dependent vascular inflammation. Proc Am Thorac Soc 5:820-823, 2008

30. Schatlo B, Fung C, Fathi AR, Sailer M, Winkler K, Daniel RT, et al: Introducing a nationwide registry: the Swiss study on aneurysmal subarachnoid haemorrhage (Swiss SOS). Acta Neurochir (Wien) 154:2173-2178, 2012

31. Schoenborn CA, Adams PE: Health behaviors of adults: United States, 2005-2007. Vital Health Stat 10:1-132, 2010

32. Singh PK, Marzo A, Howard B, Rufenacht DA, Bijlenga P, 
Frangi AF, et al: Effects of smoking and hypertension on wall shear stress and oscillatory shear index at the site of intracranial aneurysm formation. Clin Neurol Neurosurg 112:306-313, 2010

33. Thompson BG, Brown RD Jr, Amin-Hanjani S, Broderick JP, Cockroft KM, Connolly ES Jr, et al: Guidelines for the Management of Patients With Unruptured Intracranial Aneurysms: A Guideline for Healthcare Professionals from the American Heart Association/American Stroke Association. Stroke 46:2368-2400, 2015

34. Upchurch GR Jr, Schaub TA: Abdominal aortic aneurysm. Am Fam Physician 73:1198-1204, 2006

35. Vlak MH, Algra A, Brandenburg R, Rinkel GJ: Prevalence of unruptured intracranial aneurysms, with emphasis on sex, age, comorbidity, country, and time period: a systematic review and meta-analysis. Lancet Neurol 10:626-636, 2011

36. Vlak MH, Rinkel GJ, Greebe P, Algra A: Independent risk factors for intracranial aneurysms and their joint effect: a case-control study. Stroke 44:984-987, 2013

37. Vlak MH, Rinkel GJ, Greebe P, Algra A: Risk of rupture of an intracranial aneurysm based on patient characteristics: a case-control study. Stroke 44:1256-1259, 2013

38. Vourla E, Filis A, Cornelius JF, Bostelmann R, Turowski B, Kalakoti P, et al: Natural history of de novo aneurysm formation in patients with treated aneurysmatic subarachnoid hemorrhage: a ten-year follow-up. World Neurosurg 122:e291e295, 2019

39. Wiebers DO, Whisnant JP, Huston J III, Meissner I, Brown RD Jr, Piepgras DG, et al: Unruptured intracranial aneurysms: natural history, clinical outcome, and risks of surgical and endovascular treatment. Lancet 362:103-110, 2003

40. Yoon BNR, Lee JB, Jin GH, Kim WY: Serum cadmium level is positively associated with unruptured intracranial aneurysm incidence. Korean J Fam Med [epub ahead of print], 2019
41. Zatoński W, Przewoźniak K, Sulkowska U, West R, Wojtyła A: Tobacco smoking in countries of the European Union. Ann Agric Environ Med 19:181-192, 2012

\section{Disclosures}

The authors report no conflict of interest concerning the materials or methods used in this study or the findings specified in this paper.

\section{Author Contributions}

Conception and design: Bijlenga, Schatlo, Pereira, Schaller. Acquisition of data: Bijlenga, Schatlo, Friedrich, Jägersberg, Kulcsar, Pereira, Schaller. Analysis and interpretation of data: Bijlenga, Schatlo, Friedrich, Ebeling, Schaller. Drafting the article: Bijlenga, Schatlo, Gautschi. Critically revising the article: Bijlenga, Schatlo, Gautschi, Friedrich, Kulcsar, Pereira, Schaller. Reviewed submitted version of manuscript: Bijlenga, Schatlo, Gautschi, Friedrich, Jägersberg, Pereira, Schaller. Statistical analysis: Bijlenga, Friedrich, Ebeling. Administrative/technical/ material support: Bijlenga, Jägersberg, Schaller. Study supervision: Bijlenga, Schaller.

\section{Correspondence}

Philippe Bijlenga: University Hospital Geneva, Switzerland. philippe.bijlenga@hcuge.ch. 